\title{
Vaginal dinoprostone and misoprostol are equally safe in labour induction at term whereas dinoprostone is less efficacious for cervical ripening and shortening the time of labour
}

\author{
Maciej Zietek ${ }^{1}\left(\mathbb{D}\right.$, Malgorzata Swiatkowska-Freud $\left.^{2} \mathbb{(}\right)$, Kinga Grajnert ${ }^{1}(\mathbb{D}$, \\ Zbigniew Celewicz ${ }^{1}$, , Malgorzata Szczuko ${ }^{3}$ \\ ${ }^{1}$ Department of Perinatology, Obstetrics and Gynecology, Pomeranian Medical University, Szczecin, Poland \\ ${ }^{2}$ Department of Obstetrics, Medical University in Gdansk, Poland \\ ${ }^{3}$ Department of Human Nutrition and Metabolomics, Pomeranian Medical University in Szczecin, Poland
}

\begin{abstract}
Objectives: The aims of the study is to analyze the effectiveness and safety of the use of intravaginal inserts with prostaglandin analogues: dinoprostone and misoprostol, in the labor induction.

Material and methods: Pregnant women (177), with use of dinoprostone $(n=69)$ or misoprostol $(n=108)$ for labor induction were analyzed.

Results: The length of time of delivery differed significantly between primiparous and multiparous women and depended on the type of prostaglandin. The incidence of cesarean sections did not differ significantly in analysed groups. The risk of failed induction was over two-fold higher in the dinoprostone group as compared to misoprostol. A statistically significant longer duration of the first and second stage of labor was observed in primiparous compared to multiparous women as well as differences of cervical ripening were observed. There was no statistically significant relationship between the occurrence of hyperstimulation and worsening the newborns condition determined after delivery.

Conclusions: Vaginal dinoprostone and misoprostol are equally safe in labor induction at term whereas dinoprostone is less efficacious for cervical ripening and shortening the time of labor. There was no advantage of any of the prostaglandins used in increasing the risk of having a child in a worse condition and increasing the percentage of caesarean sections.
\end{abstract}

Key words: dinoprostone; misoprostol; labor induction

Ginekologia Polska 2021; 92, 6: 428-435

\section{INTRODUCTION}

Labor induction is one of the most common procedures carried in obstetrics, and its main goal is to reduce the perinatal risk of a pregnant woman or her newborn through earlier pregnancy termination [1]. The development of perinatal surveillance techniques and popularization of ultrasound diagnostic methods in perinatology significantly contributed to the more frequent decisions about these procedures. Labor induction is usually preceded by biochemical process leading to a multitude of changes of the cervix, referred as softening and repining $[2,3]$. Of the many available possibilities, the intravaginal administration of prostaglandins (PG) is one of the most used methods [1]. About $10 \%$ of pregnant women undergo induction of labor preceded by ripening of the cervix and acceleration of its maturation with the use of PGE2 prostaglandins or their analogues [3]. The response of the cervix to prostaglandins differs in women and depends on its condition at the time of drug administration, week of gestation and individual characteristics. The overall risk of ineffective preparation of the cervix within 12-24 hours of labor induction following the administration of vaginal prostaglandins (vPG) is $21.6 \%$ [4]. The cervical repining process begins several weeks before the onset of delivery, when an increase in the concentration

\footnotetext{
Corresponding author:

Maciej Zietek

Department of Perinatology, Obstetrics and Gynecology, Pomeranian Medical University, Szczecin, Poland

e-mail: maciejzietek@tlen.pl
}

This article is available in open access under Creative Common Attribution-Non-Commercial-No Derivatives 4.0 International (CC BY-NC-ND 4.0) license, allowing to download articles and share them with others as long as they credit the authors and the publisher, but without permission to change them in any way or use them commercially. 
of proinflammatory myeloid and lymphoid phenotypes related cytokines, chemotaxis regulators and factors inducing oxidative stress is observed [5,6]. In turn, the lack of collagen cross-linked degradation together with the reduction of cell nuclei density in the stroma and the depletion of macrophage resources suggests blocking the cervical ripening process [2]. Macrophages, as myeloid-derived immune cells, play an important regulatory role in the cervical tissue. Macrophages also have ability to produce nitric oxide (NO) and prostaglandins. Reduction in NO and PG synthesis inhibits the cervix maturation process. The inflammatory response process is particularly visible during the dilatation phase of the cervix, where an increase in inducible oxide synthetase (iNOS) is observed. Increased iNOS concentration enhances vasodilation, a mechanism facilitating tissue perfusion during labor and leukocyte inflow [7]. The presence of pro-inflammatory cells in the cervix in the antenatal period enables the action of paracrine factors (cytokines) influencing changes in the structure of the extracellular matrix. According to current research data, the cervical remodeling process is completed before delivery. Fibrous collagen from the stroma extracellular matrix is replaced by less cross-linked collagen [2]. The rearrangement and realignment of collagen fibrils as well as glycosaminoglycan composition changes are first components of labor induction. High endogenous PG concentration in the cervix is due to increased cyclooxygenase-2 (COX-2) activity, detected particularly before delivery. Contrary to COX-2, a decrease of 15-prostaglandin dehydrogenase (15-PGDH) has been observed, the role of which is to inactivate PG during and before the cervix maturation process $[3,8]$. Excessively active 15-PGDH is therefore associated with the ineffective action of both endogenous and exogenous PG [3].

Exogenous PG, dinoprostone (PGE2 analog) and misoprostol (PGE1 analog), acting through receptors, stimulate signaling processes in various cells of the cervix [3].

\section{MATERIAL AND METHODS}

Out of the group of 800 women giving birth in the second half of 2019 in the Department of Perinatology, Obstetrics and Gynecology, 177 (22,1\%) pregnant women were qualified for the observational study, who were between $36+3$ and $42+1$ weeks of gestation (Tab. 1). Among the analyzed group of patients, 141 (79,7\%) were primiparous, and $36(20,3 \%)$ multiparous women. All examined women had an unfavorable cervix for labor, determined by Bishop's score from 0 to 6 points (Mean 2,3) and required intravaginal administration of vPG in the form of an insert: Misoprostol (Misodel) at a dose of $200 \mu \mathrm{g}(\mathrm{n}=108)$ or Dinoprostone (Cervidil) at a dose of $10 \mathrm{mg}(\mathrm{n}=69)$ [reference group (vM) or study group(vD), respectively]. Exclusion study criteria were contraindications to the use of vPG: previous caesar-

\begin{tabular}{|c|c|c|c|c|}
\hline \multicolumn{2}{|c|}{ Parameter } & $v M(n=108)$ & $v D(n=69)$ & $\mathbf{p}$ \\
\hline \multicolumn{2}{|c|}{ Age [years] } & $23.8 \pm 4.10$ & $24.79 \pm 4.94$ & N.S. \\
\hline \multicolumn{2}{|c|}{ Maternal weight [kg] } & $68.2 \pm 9.11$ & $70.1 \pm 5.18$ & N.S. \\
\hline \multirow{2}{*}{$\begin{array}{l}\text { BMI } \\
{\left[\mathrm{kg} / \mathrm{m}^{2}\right]}\end{array}$} & $<30.0(n=166)$ & 103 (95.4\%) & $63(91.3 \%)$ & \multirow{2}{*}{ N.S } \\
\hline & $\geq 30.0(n=11)$ & $5(4.6 \%)$ & $6(8.7 \%)$ & \\
\hline \multicolumn{2}{|c|}{$\begin{array}{l}\text { Gestational age [week] } \\
\text { (range) }\end{array}$} & $\begin{array}{c}39.8 C 1.2 \\
(36.3-42.1)\end{array}$ & $\begin{array}{c}39.6 \pm 1.1 \\
(37.1-41.6)\end{array}$ & N.S. \\
\hline \multirow{2}{*}{ Parity } & Primipara $(n=36)$ & $23(21.3 \%)$ & $13(18.8 \%)$ & N.S. \\
\hline & Multipara $(n=141)$ & 85 (78.7\%) & $56(81.2 \%)$ & N.S. \\
\hline \multicolumn{2}{|c|}{$\begin{array}{l}\text { Birthweight [g] } \\
\text { (range) }\end{array}$} & $\begin{array}{c}3444 \pm 509 \\
(1660-4575)\end{array}$ & $\begin{array}{l}3518 \pm 400 \\
(2590-4580)\end{array}$ & N.S. \\
\hline
\end{tabular}

${ }^{*} \mathrm{p}<0.05 ; \mathrm{vM}$ - reference group; vD — study group; N.S. — not significant

ean section or scarred uteri, abnormal placenta implantation, non-cephalic presentation, fetal distress syndrome, cephalopelvic disproportion. Women with premature rupture of membranes have been also excluded from the study analysis.

The indications for labour induction were based on $A$ and $B$ grade recommendations and consistent in all the pregnant women (Tab. 2).

Following administration of vPG, the continuous evaluation of the fetus has been performed with cardiotocography in all women. At the start of regular uterine contractions (more than three uterine contractions in the period of 10 minutes), the vPG has been retrieved and the patient was transferred to the delivery unit. In cases of fetal distress syndrome, fetal life-threatening signs, uterine tachysystole with fetal heart rate involvement or other indications for urgent termination of pregnancy, a caesarean section has been immediately performed.

The study was approved by the ethical committee of Pomeranian Medical University and informed consent was obtained from all individual participants included in the study.

\section{Statistical analysis}

All continuous variables were checked for the normality of the distribution using the Kolmogorov-Smirnow test. The Student's or Mann-Whitney's t-tests were used to analyze statistical differences in the scores of two or more groups. To gain information about the relationship between the dependent and independent variables, the analysis of variance (ANOVA) or Kruskal-Wallis test was used. The $x 2$ Pearson test or Fisher's exact test was used to study the statistical relationships between discontinuous variables and determine if there are nonrandom associations between two categorical variables. In order to estimate the risk of pathology depending on various factors, a logistic regression model was used. The results were described by giving the relative risk (OR) along with the $95 \%$ confidence intervals and the 


\begin{tabular}{|c|c|c|c|}
\hline Indication & $\begin{array}{c}v M \\
(n=108) \\
n(\%)\end{array}$ & $\begin{array}{c}\text { vD } \\
(n=69) \\
n(\%)\end{array}$ & $\begin{array}{c}\text { TOTAL } \\
(n=177) \\
n(\%)\end{array}$ \\
\hline $\begin{array}{l}\text { Gestational diabetes } \\
\text { mellitus } \\
\text { Primipara }(n=21) \\
\text { Multipara }(n=22)\end{array}$ & $\begin{array}{c}18(16.7) \\
15 \\
3\end{array}$ & $\begin{array}{c}25(36.2) \\
6 \\
19\end{array}$ & $43(24.3)$ \\
\hline $\begin{array}{l}\text { Post term pregnancy } \\
\text { Primipara }(n=3) \\
\text { Multipara }(n=31)\end{array}$ & $\begin{array}{c}22(20.4) \\
2 \\
20\end{array}$ & $\begin{array}{c}12(17.4) \\
1 \\
11\end{array}$ & 34 (19.2) \\
\hline $\begin{array}{l}\text { Oligohydramnion } \\
\text { Primipara } \\
\text { Multipara }(n=20)\end{array}$ & $\begin{array}{c}14(13) \\
0 \\
14\end{array}$ & $\begin{array}{c}6(8.7) \\
0 \\
6\end{array}$ & $20(11.3)$ \\
\hline $\begin{array}{l}\text { Gestational } \\
\text { hypertension } \\
\text { Primipara }(n=4) \\
\text { Multipara }(n=10)\end{array}$ & $\begin{array}{c}8(7.4) \\
2 \\
6\end{array}$ & $\begin{array}{c}6(8.7) \\
2 \\
4\end{array}$ & $14(7.9)$ \\
\hline $\begin{array}{l}\text { Decreased fetal } \\
\text { movements or } \\
\text { Suspicious CTG } \\
\text { trace } \\
\text { Primipara } \\
\text { Multipara }(n=14)\end{array}$ & $\begin{array}{c}14(13) \\
0 \\
14\end{array}$ & 0 & $14(7.9)$ \\
\hline $\begin{array}{l}\text { Pregestational } \\
\text { diabetes mellitus } \\
\text { Primipara }(n=4) \\
\text { Multipara }(n=8)\end{array}$ & $\begin{array}{c}8(7.4) \\
0 \\
8\end{array}$ & $\begin{array}{c}4(5.8) \\
4 \\
0\end{array}$ & $12(6.8)$ \\
\hline $\begin{array}{l}\text { Fetal growth } \\
\text { restriction } \\
\text { Primipara }(n=4) \\
\text { Multipara }(n=2)\end{array}$ & $\begin{array}{c}6(5.6) \\
4 \\
2\end{array}$ & 0 & $6(3.4)$ \\
\hline $\begin{array}{l}\text { Others } \\
\text { Primipara } \\
\text { Multipara }(n=34)\end{array}$ & $\begin{array}{c}18(16.7) \\
0 \\
18\end{array}$ & $\begin{array}{c}16(23.2) \\
0 \\
16\end{array}$ & $34(19.2)$ \\
\hline
\end{tabular}

*Intrapartum care: NICE guideline CG190 (February 2017); VM — reference group; vD - study group

probability. The probability in this model was calculated with the $x^{2}$ Pearson test or with Fisher's two-sided test. The ROC (Receiver Operating Characteristic Curves) analysis was used to estimate the sensitivity and specificity for individual ranges of the continuous variable values. The results were described by specifying the area under the curve, the probability $p$, and the coordinates of the ROC curves. Statistically significant differences in all tests were considered those for which the probability $p<0.05$. Statistical analyzes were performed using the statistical program STATA 11, license number 30110532736.

\section{RESULTS}

Our study analysis has demonstrated that the length of time from VPG administration to the onset of regular uterine contractions depended on the type of drug administered and differed significantly between primiparous and multiparous women. In primiparous women who received
$\mathrm{vM}$, the mean time to uterine contractions was statistically significantly shorter $(p=0.0173)$ compared to the vD group and amounted to $18.16 \pm 24.04 \mathrm{~h}$ vs $22.73 \pm 36.43 \mathrm{~h}$, respectively. On the other hand, in the group of multiparous women, the time to uterine contractions, both after vM and vD administration, did not differ significantly (Fig. 1).

In the group of all examined patients, 108 (61.02\%) women gave birth by vaginal delivery, while 69 (38.98\%) had a caesarean section. When analyzing the method of termination of pregnancy, the percentage of caesarean sections did not differ significantly $(p=0.506)$ in both groups of women receiving vD 29 (42.03\%) and vM 40 (37.04\%), which proves that both drugs show comparable influence on the effectiveness of vaginal delivery. The most frequent indications for caesarean section were: failure to progress in labor 25 (14.12\%), fetal distress syndrome 19 (10.73\%), cervical dystocia 15 (8.47\%), fetal pelvic disproportion 4 (2.26\%), fetal malposition 2 (1.13\%), Indications for operative vaginal delivery (forceps or vacuum) were made in 7 (3.95\%) women. The risk assessment of the presence of several factors in the group of women treated with vD compared to those treated with vM is presented in Table 3.

The risk of failed induction was over two-fold higher in the VD group as compared to VM and this relationship was statistically significant. In those cases, further medical procedures to increase the uterine contractibility have been required: oxytocin infusion or amniotomy. In the vD multipara group, the induction failure was more frequent than in the vM multipara group ( $25 \%$ vs $12,9 \%$, respectively) (Tab. 4).

Compared to vM, the group of women receiving vD had also higher risk tendency of caesarean section or vaginal operative delivery, but this relationship was statistically insignificant. There was an over two-fold higher risk of failure to progress with $\mathrm{vD}$ compared to $\mathrm{VM}$ and this relationship was at the limit of statistical significance. In turn, the risk of a successful pre-induction was reduced $(O R=0.23)$ in the vD group compared to the vM group (Tab. 5).

In the group of women treated with both $\mathrm{VM}$ and $\mathrm{VD}$, a statistically significant longer duration of the first stage of labor ( $p=0.0028$ ) was observed in primiparous women (vM $5.93 \mathrm{~h}$; vD $6.33 \mathrm{~h}$ ) compared to multiparous women (vM 3.34 h; vD 3.49 h) (Fig. 2).

Similar relationships were observed in the second stage of labor. In the group of women treated with both vM and vD, a statistically significantly longer duration of the first stage of labor ( $p=0.0001$ ) was observed in primiparous women (vM $0.81 \mathrm{~h}$; vD $1.06 \mathrm{~h}$ ) compared to multiparous women (vM 0.26 h; vD 0.34 h) (Fig. 3).

In order to determine the cut-off value of continuous variables with respect to the drug ( $v D, v M)$, the ROC analysis was used. In primiparous women with a duration of labor $\geq 22.28$ h, the sensitivity for vD was $69 \%$. In turn, only $36 \%$ 


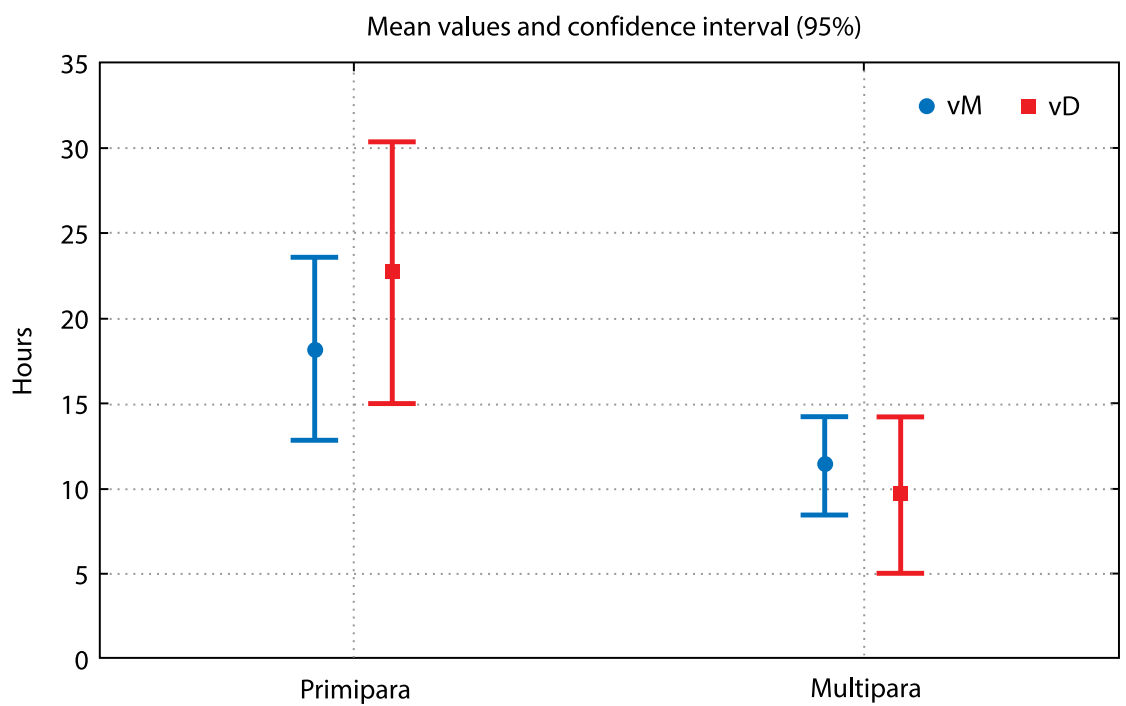

Figure 1. Mean time since the vaginal prostaglandins administration to the beginning of labour in primipara and multipara groups; vD - study group; $\mathrm{vM}$ - reference group

Table 3. Determination of confidence interval for odds ratio as a measure of association between the presence of risk factors and their occurrence in the study group compared to reference group, calculated using the $x 2$ Pearson's test or Fisher's two-sided exact test

\begin{tabular}{|l|l|c|c|c|c|c|}
\hline Dependent Variable & Risk factors & OR & [95\%] & Cl & p \\
\hline & Induction of labour followed by amniotomy & 2.18 & 1.11 & 4.27 & 0.023 \\
\hline & Induction of labour followed by oxitocin infusion & 2.61 & 1.36 & 5.01 & 0.004 \\
\hline & Successful preinduction followed by vaginal birth & 0.23 & 0.00 & 0.93 & 0.042 \\
\hline & Caesarean section & 1.23 & 0.66 & 2.28 & N.S. \\
\hline \multirow{2}{*}{$\begin{array}{l}\text { Occurrence in the vD group } \\
\text { compared to vM grouzp }\end{array}$} & Vaginal operative delivery & 1.18 & 0.26 & 5.45 & N.S. \\
\cline { 2 - 7 } & Cephalopelvic disproportion. & 1.58 & 0.22 & 11.50 & N.S. \\
\cline { 2 - 7 } & Failure to progress in labour & 2.24 & 0.95 & 5.28 & 0.064 \\
\cline { 2 - 7 } & Fetal distress & 0.90 & 0.34 & 2.42 & N.S. \\
\cline { 2 - 6 } & Cervical dystocia & 0.54 & 0.17 & 1.78 & N.S. \\
\hline
\end{tabular}

vM - reference group; $v D$ - study group; N.S. - not significant

\begin{tabular}{|c|c|c|c|c|}
\hline \multirow{3}{*}{ vM } & & $\begin{array}{c}\text { Multipara } \\
\text { n (\%) }\end{array}$ & $\begin{array}{c}\text { Primipara } \\
n(\%)\end{array}$ & $\mathbf{p}$ \\
\hline & Normal labor progress $(n=97)$ & $74(87.1)$ & $23(100)$ & \multirow{2}{*}{ N.S } \\
\hline & Failure to progress $(n=11)$ & $11(12.9)$ & 0 & \\
\hline \multirow{2}{*}{ vD } & Normal labor progress $(n=55)$ & $42(75)$ & $13(100)$ & \multirow{2}{*}{0.04} \\
\hline & Failure to progress $(n=14)$ & $14(25)$ & 0 & \\
\hline
\end{tabular}

$\mathrm{vM}$ - reference group; $\mathrm{vD}$ - study group; N.S. - not significant

of respondents who received $v M$ had a delivery time $\geq 22.28 \mathrm{~h}$ (Specificity). For primiparous women, vD vs vM has a statistically significantly increased risk of prolonging the period of labor (first and second stage of labor time prolongation).

Statistically significant differences in cervical ripening were observed on the Bishop Score after administration of both vM and vD in primiparous and multiparous groups (Tab.6), which proves that both drugs show high effectiveness in the area of the cervical tissue. In the group of primiparous women where a pregnancy was terminated by caesarean section, significantly lower Bishop score values were observed in comparison with vaginal deliveries, which indicates that the effectiveness of vaginal labor depends on the cervical ripening. This relationship was not observed in multiparous women. 
There were no significant differences between analyzed groups of women for postpartum hemorrhage and the rate was $18.5 \%(n=20)$ and $20.3 \%(n=14)$ for vM and vD respectively. There was also no statistically significant correlation between the newborns' birth condition in the Apgar score (3rd and 5th min.) on the degree of cervical ripening. The babies' condition after birth has not been also related to the type of drug administered, duration of the I and II stage of labour, and the time from drug administration to delivery. Uterine hyperstimulation, understood as uterine contraction followed by pathological CTG recordings, oc-

Table 5. Relationships between vPG and cervical repining according to the Bishop score (BS) in the studied groups of women

\begin{tabular}{|c|c|c|c|c|c|}
\hline Para & VPG & BS & $\mathbf{n}$ & $\begin{array}{l}\text { The mean } \pm \text { SD BS } \\
\text { difference before } \\
\text { and after vPG } \\
\text { administration }\end{array}$ & $\mathbf{p}$ \\
\hline \multirow{2}{*}{ Primipara } & $\mathrm{vM}$ & $\begin{array}{l}<4 \\
4-9 \\
>9\end{array}$ & $\begin{array}{l}18 \\
52 \\
12\end{array}$ & $\begin{array}{l}0.78 \pm 0.81 \\
3.60 \pm 2.34 \\
8.33 \pm 3.34\end{array}$ & 0.0001 \\
\hline & vD & $\begin{array}{l}<4 \\
4-9 \\
>9\end{array}$ & $\begin{array}{c}21 \\
27 \\
8\end{array}$ & $\begin{array}{l}0.67 \pm 0.97 \\
3.89 \pm 2.17 \\
7.75 \pm 2.12\end{array}$ & 0.0001 \\
\hline \multirow{2}{*}{ Multipara } & $\mathrm{vM}$ & $\begin{array}{l}<4 \\
4-9 \\
>9\end{array}$ & $\begin{array}{c}1 \\
13 \\
9\end{array}$ & $\begin{array}{c}0 \\
3.31 \pm 2.29 \\
9.11 \pm 3.82\end{array}$ & 0.0004 \\
\hline & vD & $\begin{array}{l}<4 \\
4-9 \\
>9\end{array}$ & $\begin{array}{l}1 \\
5 \\
5\end{array}$ & $\begin{array}{c}0 \\
4.40 \pm 2.61 \\
7.80 \pm 1.48\end{array}$ & 0.0177 \\
\hline
\end{tabular}

$\mathrm{vD}$ — study group; $\mathrm{vM}$ - reference group curred in 14 (7.91\%) women: 10 in vM and 4 in vD and the difference was not statistically significant $(p=0.69)$ in compared groups of patients. There was also no statistically significant relationship between the occurrence of hyperstimulation and parity, and its occurrence was not associated with worsening of newborns 'condition determined at the $3^{\text {rd }}$ and $5^{\text {th }}$ minutes of Apgar $(p=0.33)$ after delivery.

\section{DISCUSSION}

The mean percentage of induced labour is in the range of about 20-25 percent, which signifies that every fifth pregnant woman is qualified to pregnancy termination before the onset of spontaneous uterine contractions [9]. In our material, this percentage was similar and did not differ from the data of other authors. Although the fetal-maternal indications for labour induction are well defined, there is still no clear consensus as to which of the available methods should be used. In our material, one of the most common indications for induction of labour was post-term pregnancy, which is consistent with the reports of other authors [10]. Mostly, pharmacological (prostaglandin analogs), mechanical (eg Foley catheter) or simultaneously both methods are commonly used for labour induction [11].

In the case of labor induction, a particularly important element for the successful delivery is cervical ripening, a dynamic process accelerated by both endogenous and exogenous prostaglandins $[3,4,11]$. It seems that the ripening of the cervix determines the quality and duration of labour as well as the need for additional stimulation of uterine contractions with oxytocin and the use of analgesics. Prostaglandins may be applied in the form of a gel to the cervical canal, vaginal insert or orally/ buccally titrated tablets. The most used are propstaglandin E1 E2 analogs:

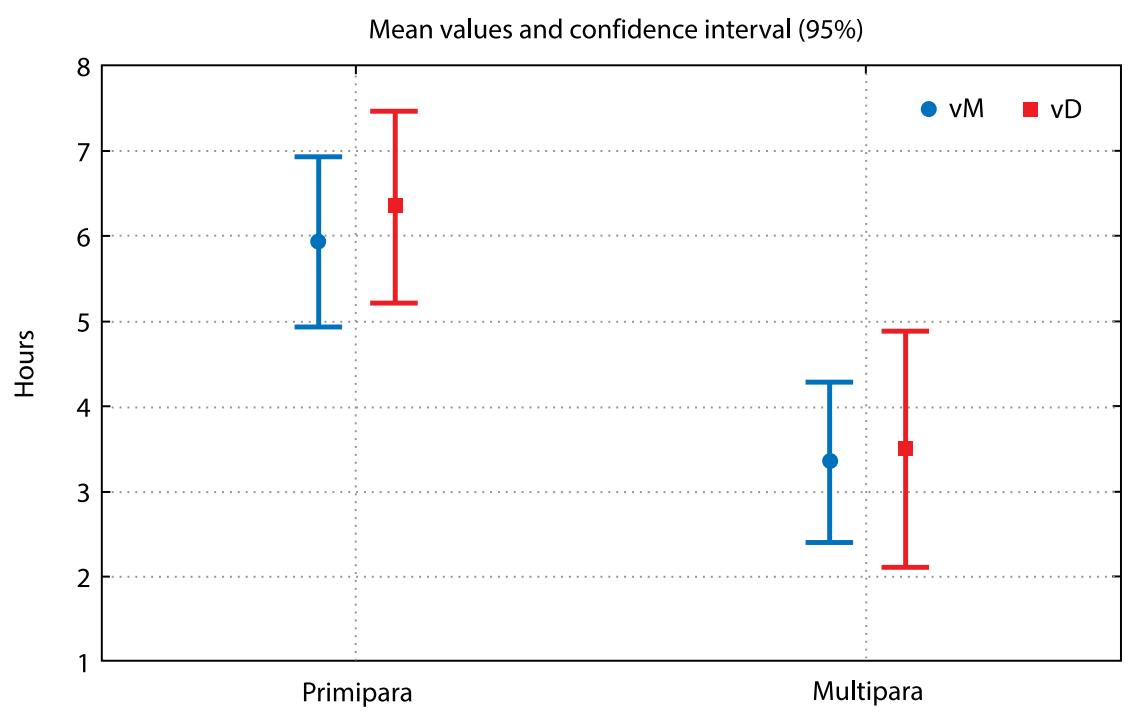

Figure 2. Mean time of the $1^{\text {st }}$ stage of labour in primipara and multipara groups; vD — study group; vM — reference group 


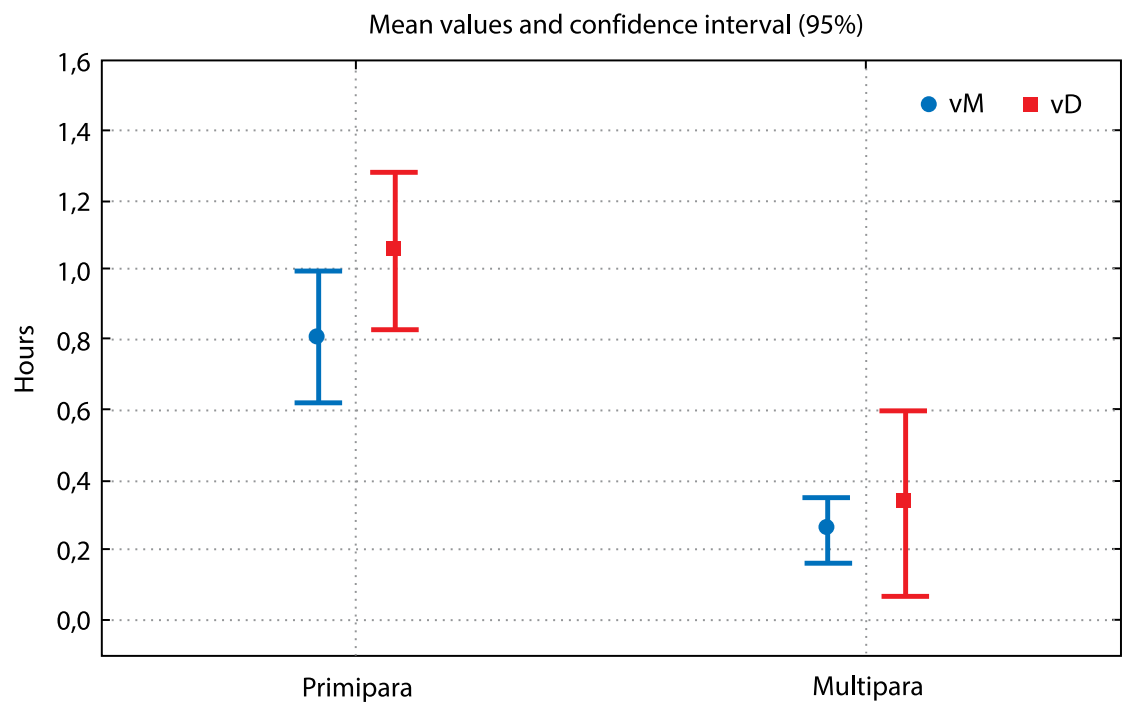

Figure 3. Mean time of the $2^{\text {nd }}$ stage of labour in primipara and multipara groups; $\mathrm{VD}$ - study group; $\mathrm{VM}$ - reference group

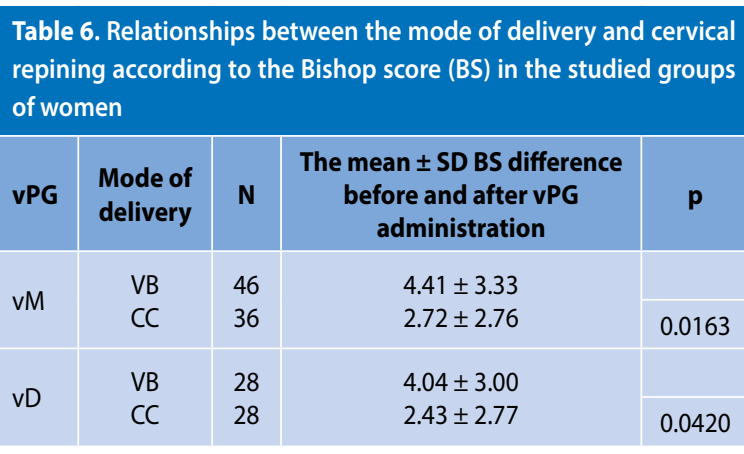

vPG — vaginal prostaglandins; VB — vaginal birth; CC — caesarean section; $\mathrm{VD}$ - study group; $\mathrm{vM}$ - reference group

misoprostol and dinoprostone respectively [12]. Both drugs, apart from inducing uterine contractions, play a critical role in cervical ripening and softening $[3,9,11]$. Studies by Melamed et al. [13] proved that after prostaglandin E2 administration in a dose of $3 \mathrm{mg}$, an effective cervical ripening with favourable cervix to delivery was not achieved in $25 \%$ of pregnant women. The cervical ripening is a complex biochemical reaction, the mechanism of action of which is still not fully understood. An inflammatory process probably plays an important role, accompanied by an increase in the immune activity of cells and a change in their functions [14]. Yoshida et al. [15] found in an animal model that the softening phase of cervical remodeling is related to the decline of collagen cross-link density. At the same time, increased hydration of cervical cells was observed. This process may be modulated by changes in sex hormone levels leading to the activation of immune cells. In our study, a positive correlation was observed between the cervical ripening expressed with the Bishop scale and vaginally administrated prostaglandins. Our re- sults, however, showed different dynamics of the action of two compared drugs. Misoprostol has shown greater effectiveness compared to dinoprostone, which is consistent with studies by other authors [16-18]. Its higher efficiency is manifested by a significant shortening of the delivery time, both in the first and the second stage of labor [18]. In consequence of a shortened stay in the maternity ward with accelerated delivery, the risk of vaginal operative delivery and cervical dystocia is reduced, as our research has also shown. It was calculated that vPG (especially vM versus $\mathrm{VD}$ ) shortened the mean reduction in bed hours by nine and six hours in primiparous and multiparous women, respectively [18]. According to reports by other authors, shortened labour time reduces the risk of maternal infection and the need for antibiotics use [19]. In our studies, the mean time from vPG administration to the onset of labour differed significantly between primiparous and multiparous women. In the studies by Shmid et al. [17], similar statistically significant relationships were obtained: 14.9 hours of primiparous women and 11.8 hours of multiparous women.

According to the research literature, the use of dinorpostone compared to misoprostol is more often associated with the need to stimulate uterine contractions with oxytocin [16, 20,21], although some authors report no significant differences between these two prostaglandins use [22]. In our studies, oxytocin was used more than twice as often in the group of women induced with dinoprostone.

We found no correlation between the caesarean section rate and the type of VPG administered during labour induction. In a study by Schmidt et al. [17], caesarean section was performed in $31.1 \%$ of induced pregnancies (110/354), more often in primiparous women. In our study, the percentage of 
caesarean sections was slightly higher (38.9\%) and the most common indications for its performance were abnormal CTG recordings, no progression of labour or cervical dystocia.

There are reports that tachysystole and uterine hyperstimulation are more common in women induced with misoprostol compared to dinoprostone [22]. In a study by Wing et al. [21], tachysystole was present in $13.3 \%$ of women induced by misprostol (vaginal $200 \mathrm{mcg}$ ) vs $4.0 \%$ induced by dionoprostone (vaginal $10 \mathrm{mg}$ ). On the other hand, in the studies by Yehia et al. [20], no statistical differences were observed in the occurrence of uterine hyperstimulation in the groups of women undergoing induction with misoprostol and dinoprostone, which may be due to differences in the form and dose of drugs used: titrated oral misoprostol (20 mcg every 2 hours) and vaginal dinoprostone ( $3 \mathrm{mg}$ ). Other studies compared oral misoprostol (50mcg every 4 hours), vaginal misoprostol (25-50mcg every 6 hours) with vaginal gel dinoprostone [23] or vaginal insert dinoprostone (10 mg) [9]. In all the studied groups, the authors did not find statistically significant differences in the occurrence of tachysystole and uterine hyperstimulation. Our studies have also shown no differences in the percentage of uterine hyperstimulation in the studied groups of women. A randomized clinical trial is currently in progress regarding efficacy and safety of administering oral misoprostol by titration compared to vaginal misoprostol and dinoprostone for cervical ripening and induction of labor [24]. Most studies reports do not show any increased risk of side effects of misoprostol compared to dinoprostone, as well as worse birth condition of the newborns, longer stay on NICU admission and higher neonatal mortality after induction of labor with misoprostol or dinoprostone [20, $22,23,25]$. In randomized studies of PLOS ONE - the median birth status of newborns on the Apgar scale at the first and fifth minutes of life did not differ significantly in the groups of mothers induced with prostaglandin analogues: oral or vaginal misoprostol and vaginal dinoprostone [23]. The use of exogenous prostaglandins does not affect the birth condition of newborns, regardless of the exposure time and the time of prostaglandin removal [25]. Similar results were obtained in our study, where the condition of newborns did not differ significantly in the studied groups.

Our research shows that both prostaglandins used, vM and $v D$ are effective during labour induction and show a similar safety profile, which means that the use of pharmacological methods for labour induction may be a safe treatment alternative to other methods.

\section{CONCLUSIONS}

Vaginal dinoprostone and misoprostol are equally safe in labour induction at term whereas dinoprostone is less efficacious for cervical ripening and shortening the time of labour. There was no advantage of any of the prostaglandins used in increasing the risk of having a child in a worse condition and increasing the percentage of caesarean sections.

\section{Conflict of interest}

The authors declare no conflict of interest.

\section{REFERENCES}

1. Pierce $S$, Bakker R, Myers DA, et al. Clinical Insights for Cervical Ripening and Labor Induction Using Prostaglandins. AJP Rep. 2018; 8(4): e307-e314, doi: 10.1055/s-0038-1675351, indexed in Pubmed: 30377555.

2. Yellon SM. Immunobiology of Cervix Ripening. Front Immunol. 2019; 10: 3156, doi: 10.3389/fimmu.2019.03156, indexed in Pubmed: 32038651.

3. Kishore $\mathrm{AH}$, Liang $\mathrm{H}$, Kanchwala $\mathrm{M}$, et al. Prostaglandin dehydrogenase is a target for successful induction of cervical ripening. Proc Natl Acad Sci U S A. 2017; 114(31): E6427-E6436, doi: 10.1073/pnas.1704945114, indexed in Pubmed: 28716915.

4. Kelly AJ, Malik S, Smith L, et al. Vaginal prostaglandin (PGE2 and PGF2a) for induction of labour at term. Cochrane Database Syst Rev. 2009(4): CD003101, doi: 10.1002/14651858.CD003101.pub2, indexed in Pubmed: 19821301.

5. Menon R. Oxidative stress damage as a detrimental factor in preterm birth pathology. Front Immunol. 2014; 5: 567, doi: 10.3389/fimmu.2014.00567, indexed in Pubmed: 25429290.

6. Venkatesh KK, Cantonwine DE, Ferguson K, et al. Inflammatory and oxidative stress markers associated with decreased cervical length in pregnancy. Am J Reprod Immunol. 2016; 76(5): 376-382, doi: 10.1111/aji.12545, indexed in Pubmed: 27476489.

7. Ledingham MA, Thomson AJ, Young A, et al. Changes in the expression of nitric oxide synthase in the human uterine cervix during pregnancy and parturition. Mol Hum Reprod. 2000; 6(11): 1041-1048, doi: 10.1093/molehr/6.11.1041, indexed in Pubmed: 11044468.

8. Kishore AH, Owens D, Word RA. Prostaglandin E2 regulates its own inactivating enzyme, 15-PGDH, by EP2 receptor-mediated cervical cell-specific mechanisms. J Clin Endocrinol Metab. 2014; 99(3): 1006-1018, doi: 10.1210/jc.2013-3392, indexed in Pubmed: 24471568.

9. Cazorla MQ, Marques AP, Sanmartin J, et al. Effectiveness, safety and costs of labor induction with intravaginal misoprostol versus dinoprostone vaginal insert. Clinical Investigation. 2017; 07(01), doi: 10.4172/clinical-investigation.1000108.

10. Middleton $\mathrm{P}$, Shepherd $\mathrm{E}$, Crowther $\mathrm{C}$. Induction of labour for improving birth outcomes for women at or beyond term. Cochrane Database Syst Rev. 2018; 5(5): CD004945, doi: 10.1002/14651858.cd004945.pub4, indexed in Pubmed: 29741208.

11. Tenore JL. Methods for cervical ripening and induction of labor. Am Fam Physician. 2003; 67(10): 2123-2128, indexed in Pubmed: 12776961.

12. Leduc $D$, Biringer $A$, Lee $L$, et al. CLINICAL PRACTICE OBSTETRICS COMMITTEE, SPECIAL CONTRIBUTORS. Induction of labour. J Obstet Gynaecol Can. 2013;35(9): 840-857, doi: 10.1016/\$1701-2163(15)30842-2, indexed in Pubmed: 24099451.

13. Melamed N, Ben-Haroush A, Kremer S, et al. Failure of cervical ripening with prostaglandin-E2 can it be predicted? J Matern Fetal Neonatal Med. 2010; 23(6): 536-540, doi: 10.3109/14767050903197076, indexed in Pubmed: 19895355.

14. Barrios De Tomasi J, Opata MM, Mowa CN. Immunity in the Cervix Interphase between Immune and Cervical Epithelial Cells. J Immunol Res. 2019; 2019: 7693183, doi: 10.1155/2019/7693183, indexed in Pubmed: 31143785 .

15. Yoshida K, Reeves C, Vink J, et al. Cervical collagen network remodeling in normal pregnancy and disrupted parturition in Antxr2 deficient mice. J Biomech Eng. 2014; 136(2): 021017, doi: 10.1115/1.4026423, indexed in Pubmed: 24390076.

16. Arif R, Mazhar T, Jamil M. Induction of Labor in Primigravid Term Pregnancy with Misoprostol or Dinoprostone: A Comparative Study. Cureus. 2019; 11(9): e5739, doi: 10.7759/cureus.5739, indexed in Pubmed: 31723500

17. Schmidt M, Neophytou M, Hars $O$, et al. Clinical experience with misoprostol vaginal insert for induction of labor: a prospective clinical observational study. Arch Gynecol Obstet. 2019; 299(1): 105-112, doi: 10.1007/s00404-018-4942-y, indexed in Pubmed: 30374645. 
18. Draycott $\mathrm{T}$, van der Nelson $\mathrm{H}$, Montouchet $\mathrm{C}$, et al. Reduction in resource use with the misoprostol vaginal insert vs the dinoprostone vaginal insert for labour induction: a model-based analysis from a United Kingdom healthcare perspective. BMC Health Serv Res. 2016; 16: 49, doi: 10.1186/s12913-016-1278-9, indexed in Pubmed: 26864022.

19. Wing DA, Brown R, Plante LA, et al. Misoprostol vaginal insert and time to vaginal delivery: a randomized controlled trial. Obstet Gynecol. 2013; 122(2 Pt 1): 201-209, doi: 10.1097/AOG.0b013e31829a2dd6, indexed in Pubmed: 23857539.

20. Abdelazim I, Yehia A, Fattah IA, et al. Titrated misoprostol versus dinoprostone for labor induction. Journal of Basic and Clinical Reproductive Sciences. 2016; 5(2): 75, doi: 10.4103/2278-960x.194473.

21. Wing DA, Brown R, Plante LA, et al. Misoprostol vaginal insert and time to vaginal delivery: a randomized controlled trial. Obstet Gynecol. 2013; 122(2 Pt 1): 201-209, doi: 10.1097/AOG.0b013e31829a2dd6, indexed in Pubmed: 23857539.
22. Rankin $\mathrm{K}$, Chodankar $\mathrm{R}$, Raymond $\mathrm{K}$, et al. Misoprostol vaginal insert versus dinoprostone vaginal insert: A comparison of labour and delivery outcomes. Eur J Obstet Gynecol Reprod Biol. 2019; 235: 93-96, doi: 10.1016/j.ejogrb.2018.07.025, indexed in Pubmed: 30122321.

23. Young DC, Delaney T, Armson BA, et al. Oral misoprostol, low dose vaginal misoprostol, and vaginal dinoprostone for labor induction: Randomized controlled trial. PLoS One. 2020; 15(1): e0227245, doi: 10.1371/journal.pone.0227245, indexed in Pubmed: 31923193.

24. Lapuente-Ocamica O, Ugarte L, Lopez-Picado A, et al. Efficacy and safety of administering oral misoprostol by titration compared to vaginal misoprostol and dinoprostone for cervical ripening and induction of labour: study protocol for a randomised clinical trial. BMC Pregnancy Childbirth. 2019; 19(1): 14, doi: 10.1186/s12884-018-2132-3, indexed in Pubmed: 30621614.

25. Rugarn O, Tipping D, Powers B, et al. Induction of labour with retrievable prostaglandin vaginal inserts: outcomes following retrieval due to an intrapartum adverse event. BJOG. 2017; 124(5): 796-803, doi: 10.1111/1471-0528.14147, indexed in Pubmed: 27307397. 